\title{
A Tool to Model the Fate and Transport of Indoor Microbiological Aerosols (FaTIMA)
}

\author{
W. Stuart Dols \\ Brian J. Polidoro \\ Dustin Poppendieck \\ Steven J. Emmerich
}

This publication is available free of charge from:

https://doi.org/10.6028/NIST.TN.2095

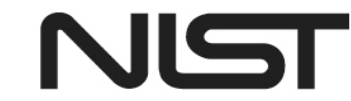

National Institute of Standards and Technology U.S. Department of Commerce 


\title{
A Tool to Model the Fate and Transport of Indoor Microbiological Aerosols (FaTIMA)
}

\author{
W. Stuart Dols \\ Brian J. Polidoro \\ Dustin Poppendieck \\ Steven J. Emmerich \\ Energy and Environment Division \\ Engineering Laboratory
}

This publication is available free of charge from:

https://doi.org/10.6028/NIST.TN.2095

June 2020

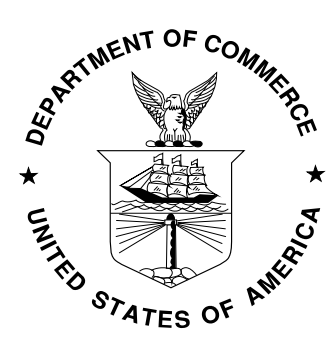

U.S. Department of Commerce

Wilbur L. Ross, Jr., Secretary

National Institute of Standards and Technology Walter Copan, NIST Director and Undersecretary of Commerce for Standards and Technology 
National Institute of Standards and Technology Technical Note 2095

Natl. Inst. Stand. Technol. Tech. Note 2095, 32 pages (June 2020)

CODEN: NTNOEF

This publication is available free of charge from:

https://doi.org/10.6028/NIST.TN.2095 


\begin{abstract}
The web-based tool Fate and Transport of Indoor Microbiological Aerosols (FaTIMA) allows the determination of the fate of indoor microbiological aerosols associated with ventilation, filtration, deposition, and inactivation mechanisms. FaTIMA provides a representation of a single, well-mixed zone that is served by a mechanical ventilation system and incorporates source and removal mechanisms for an aerosol with a single, user-defined representative particle size. The simple mechanical ventilation system model allows specification of supply, return, and outdoor air intake rates to represent either a positive, negative or balanced ventilation system. Aerosol sources are provided to enable any combination of continuous, e.g., breathing-related emissions, or intermittent, e.g., coughing-related emissions. Aerosol removal mechanisms include filters within the ventilation system, room air cleaners, and deposition onto floors, walls, and ceilings. Simulations can be run for a 24-h period, with the results including the time history of the airborne concentration and surface loading, as well as integrated exposure of an occupant. Exposure is based on a uniform aerosol concentration within the zone and does not account for spatial differences in aerosol concentrations such as those due to momentum effects of respiratory emissions.
\end{abstract}

Key Words: exposure; indoor air quality; modeling; pathogens; viruses 


\section{Disclaimer}

This tool was developed by employees of the National Institute of Standards and Technology (NIST), an agency of the Federal Government, and is being made available as a public service.

Pursuant to title 17 United States Code section 105, works of NIST employees are not subject to copyright protection in the United States. This tool may be subject to foreign copyright. Permission in the United States and in foreign countries, to the extent that NIST may hold copyright, to use, copy, modify, create derivative works, and distribute this tool and its documentation without fee is hereby granted on a non-exclusive basis, provided that this notice and disclaimer of warranty appears in all copies.

THE TOOL IS PROVIDED 'AS IS' WITHOUT ANY WARRANTY OF ANY KIND, EITHER EXPRESS, IMPLIED, OR STATUTORY, INCLUDING, BUT NOT LIMITED TO, ANY WARRANTY THAT THE TOOL WILL CONFORM TO SPECIFICATIONS, ANY IMPLIED WARRANTIES OF MERCHANTABILITY, FITNESS FOR A PARTICULAR PURPOSE, AND FREEDOM FROM INFRINGEMENT, AND ANY WARRANTY THAT THE DOCUMENTATION WILL CONFORM TO THE TOOL, OR ANY WARRANTY THAT THE TOOL WILL BE ERROR-FREE. IN NO EVENT SHALL NIST BE LIABLE FOR ANY DAMAGES, INCLUDING, BUT NOT LIMITED TO, DIRECT, INDIRECT, SPECIAL OR CONSEQUENTIAL DAMAGES, ARISING OUT OF, RESULTING FROM, OR IN ANY WAY CONNECTED WITH THIS TOOL, WHETHER OR NOT BASED UPON WARRANTY, CONTRACT, TORT, OR OTHERWISE, WHETHER OR NOT INJURY WAS SUSTAINED BY PERSONS OR PROPERTY OR OTHERWISE, AND WHETHER OR NOT LOSS WAS SUSTAINED FROM, OR AROSE OUT OF THE RESULTS OF, OR USE OF, THE TOOL PROVIDED HEREUNDER.

Users are warned that this software is intended for use only by persons competent in the field of particle exposure analysis and is intended only to supplement the judgement of the qualified user. The computer programs described in this report are prototype methodologies for computing particle exposure in buildings. The calculations are based upon a simplified model of the complexity of real buildings. These simplifications must be understood and considered by the user.

Certain commercial entities, equipment, or materials may be identified in this document in order to describe an experimental procedure or concept adequately. Such identification is not intended to imply recommendation or endorsement by the National Institute of Standards and Technology, nor is it intended to imply that the entities, materials, or equipment are necessarily the best available for the purpose. 


\section{Table of Contents}

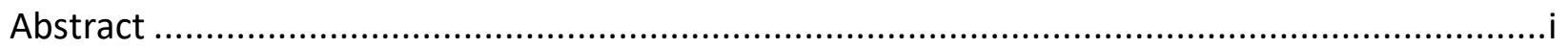

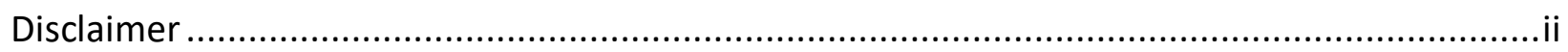

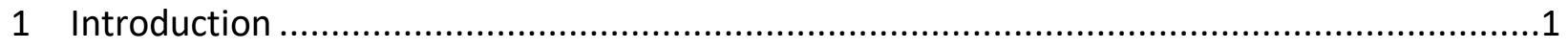

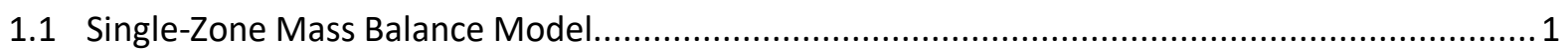

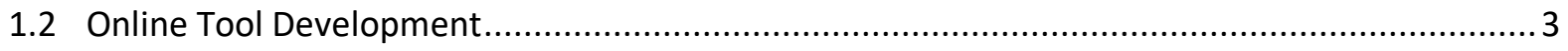

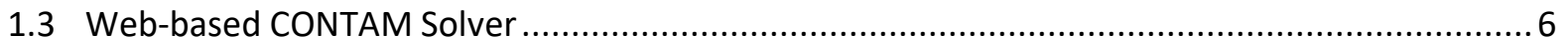

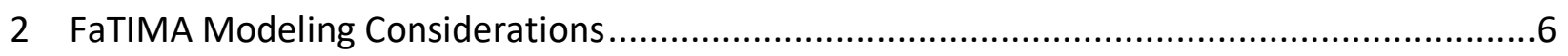

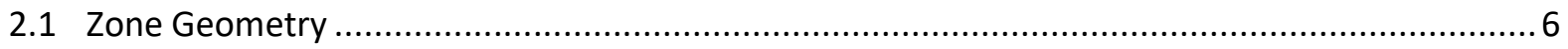

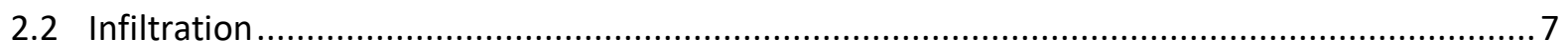

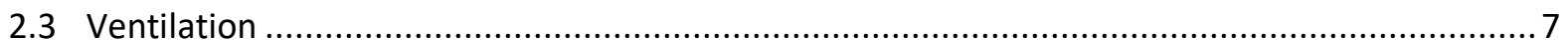

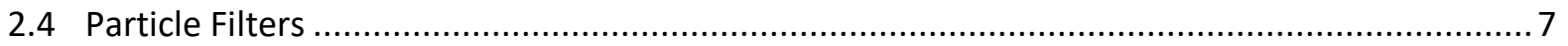

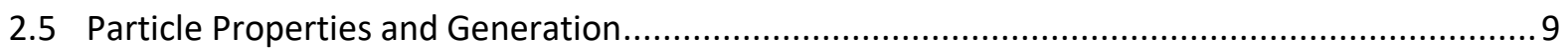

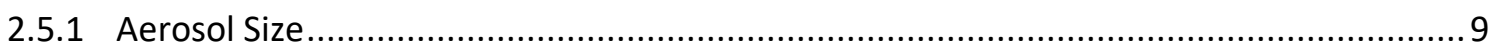

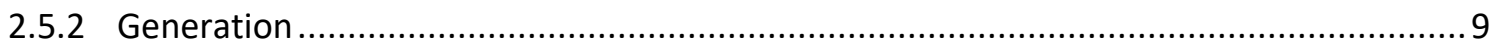

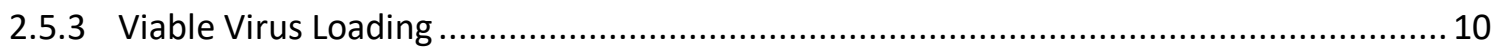

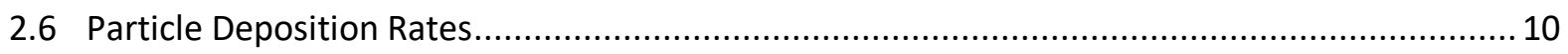

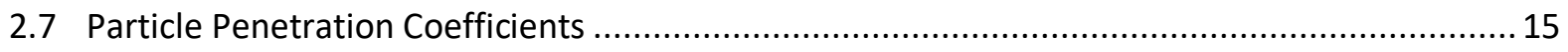

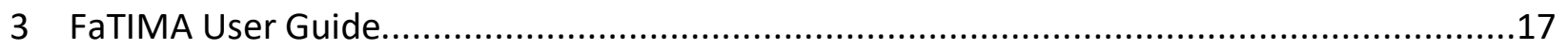

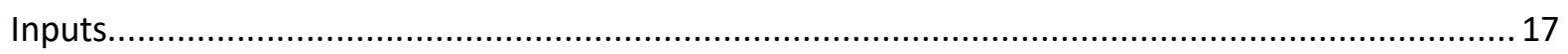

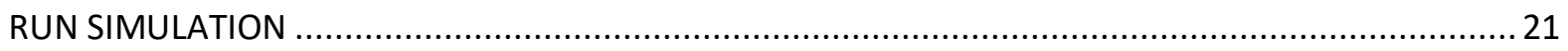

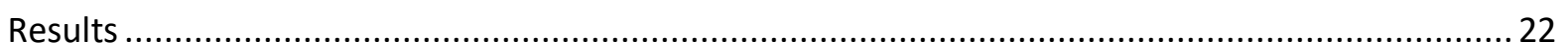

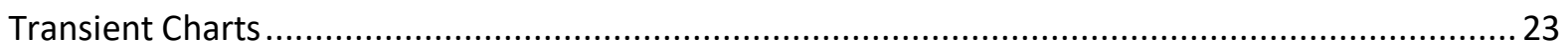

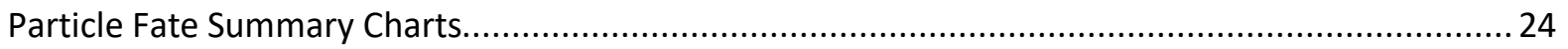

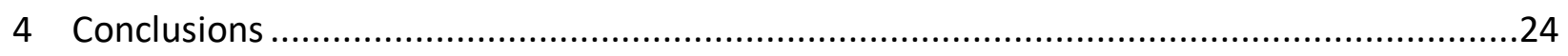

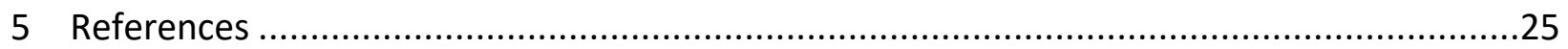




\section{Introduction}

The Fate and Transport of Indoor Microbiological Aerosols (FaTIMA) allows for the determination of the fate of indoor microbiological aerosols associated with ventilation, filtration, deposition, and inactivation mechanisms. FaTIMA provides a representation of a single, well-mixed zone that is served by a mechanical ventilation system and incorporates source and removal mechanisms for an aerosol with a single, user-defined representative particle size. The simple mechanical ventilation system model allows specification of supply, return, and outdoor air intake rates to represent either a positive, negative, or balanced ventilation system. Aerosol sources are provided to enable any combination of continuous, e.g., breathing-related emissions, or intermittent, e.g., coughing-related emissions. Aerosol removal mechanisms include filters (within the ventilation system and room air cleaners) and deposition onto floors, walls, ceilings, and other surfaces. Simulations can be run for a 24-h period, with the results including the time history of the airborne concentration and surface loading as well as integrated exposure of an occupant. FaTIMA can be accessed from the following web page:

https://pages.nist.gov/CONTAM-apps/webapps/FaTIMA/index.html

The Indoor Air Quality and Ventilation Group of the National Institute of Standards and Technology (NIST) develops software tools (NIST Multizone Modeling website) to simulate whole-building airflow and airborne contaminant transport. These tools enable users, including building designers and researchers, to address a wide range of design and analysis problems. The most powerful and sophisticated tool, CONTAM [1], requires significant user knowledge in order to develop well-formed and useful modeling representations of buildings and ventilation systems, and information on other properties relevant to the goal of the analysis, e.g., contaminant transport-related phenomenon. The purpose of this document is to present a simplified, web-based front end to CONTAM that addresses a specific class of problems and that requires little to no prior knowledge or experience with CONTAM on the part of the user.

\subsection{Single-Zone Mass Balance Model}

The underlying model for FaTIMA, shown schematically in Figure 1, consists of a single zone characterized by a uniform aerosol concentration. Users who need to understand spatial variations in aerosol concentrations should consider using computational fluid dynamics [2, 3]. In FaTIMA, an aerosol consists of a single, user-defined representative particle size; therefore, throughout this document particle refers to the representative component of an aerosol being simulated. The model implements a simple air handling system (AHS) that provides supply air to and removes return air from the zone. The supply and return airflow rates, $Q_{S}$ and $Q_{r}$ respectively, and the outdoor air fraction of the AHS are user inputs, and the AHS model determines the resulting zone air balance, including the system outdoor air intake $Q_{o a}$ and envelope infiltration $Q_{i n f}$. If the supply and return airflows are not balanced, then the zone will either be negatively or positively pressurized, which in combination with local exhaust $Q_{1 x}$, determines the infiltration rate, $Q_{i n f}$ in Equation (1).

The single-zone mass balance equations for the zone volume and interior surfaces are provided in Equations (1) and (2) respectively. Equation (1) indicates the time rate of change in mass of 
particles within the zone air is equal to the rate that particles are added to the zone air (from the outdoors via infiltration, from the supply airflow of the AHS, and directly by particle generation within the zone) minus the rate they are removed from the zone air (via the return airflow of the AHS and deposition to the room surfaces). Equation (2) indicates the time rate of change of particle mass on the surfaces of the zone is equal to the rate that particles are deposited on the surfaces. CONTAM performs all contaminant calculations in mass-based units. However, particle sources can also be input on a number basis. The tool converts between mass-based and number-based units using the user defined particle diameter and density.

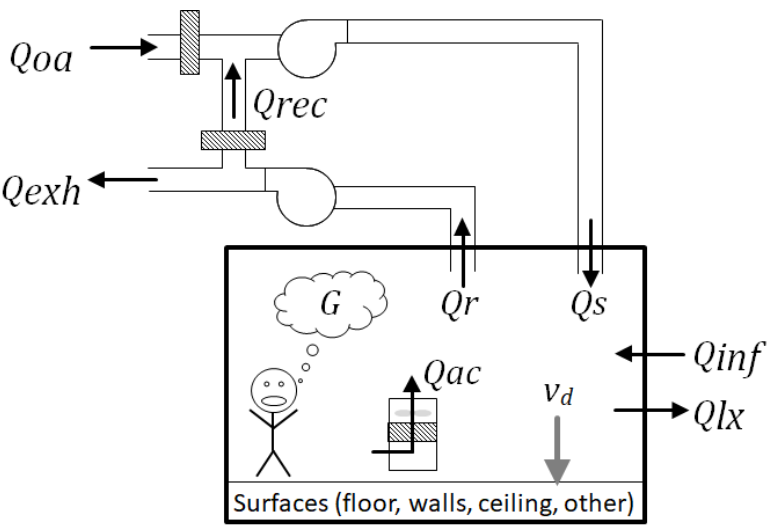

Figure 1 - Schematic of Single-zone Model

$$
V \frac{d C_{z}}{d t}=P Q_{i n f} C_{o a}(t)+Q_{s} C_{s}(t)+G(t)-\left(Q_{r}+Q_{l x}+\eta_{a c} Q_{a c}\right) C_{z}(t)-\sum_{i=1}^{N_{s}} v_{d i} A_{s i} C_{z}(t)
$$

$$
A_{s i} \frac{d L_{s i}}{d t}=v_{d i} A_{s i} C_{z}(t)
$$

where:

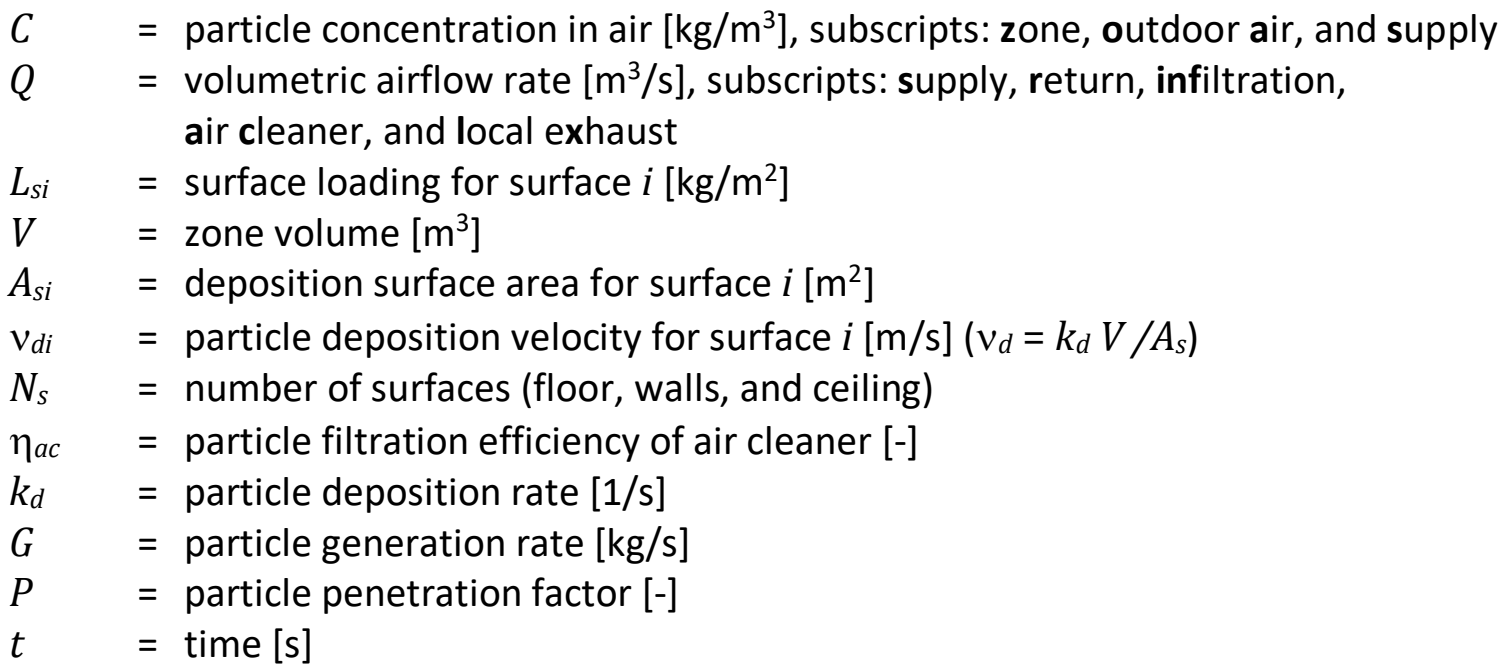




\subsection{Online Tool Development}

A single zone CONTAM model forms the basis of the online tool. The inputs to FaTIMA define the single zone CONTAM representation shown in Figure 2. After a simulation has been completed using the web tool, a CONTAM project file and comma-separated value (CSV) file can be downloaded that reflect the selected inputs and results of the simulation. The project file can then be used directly by CONTAM for those familiar with its interface, which allows the exercise of CONTAM capabilities not implemented in FaTIMA. The web interface of FaTIMA is divided into two sections: Inputs and Results as shown in Figure 3 and Figure 4, respectively. The inputs are further subdivided into Zone Geometry, Infiltration, Ventilation System, System Filters, Calculated Airflows, Room Air Cleaner, Particle Properties, Continuous Source, Burst Source, Particle Deposition Velocities, Initial Concentrations, and Occupant Exposure. Details of each input are provided in the FaTIMA User Guide section of this document.

Users set the desired inputs and then run a 24-hour simulation. Airborne and surface results are provided in the form of integrated exposure, average and maximum aerosol concentrations for the exposure period and for the full 24-hour simulation period. Charts are also provided showing the time histories of the zone concentration, exposure concentration, and surface loading. The concentration plots also show the average concentrations associated with both the exposure period and the full 24-hour period.

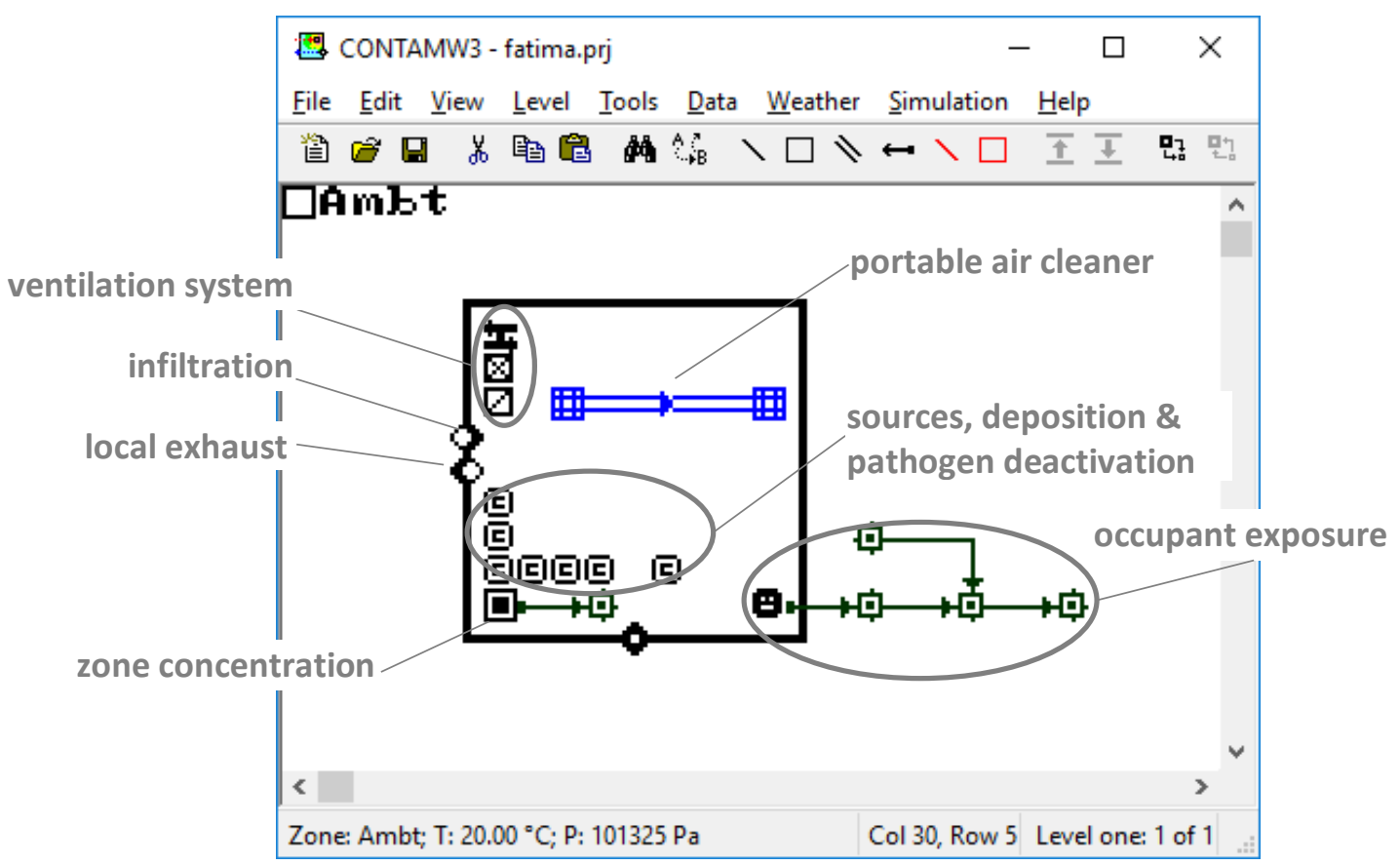

Figure 2-CONTAM Representation of Single Zone FaTIMA Model 
Fate and Transport of Indoor Microbiological Aerosols (FaTIMA)

Instructions: Set Inputs then click the RUN SIMULATION button.

Inputs

\begin{tabular}{|c|c|c|c|c|c|c|}
\hline Zone Geometry & \begin{tabular}{|l|} 
Volume \\
100 \\
\end{tabular} & 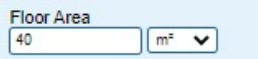 & $\begin{array}{l}\text { Wall Area } \\
\begin{array}{l}63.25 \\
\mathrm{~m}^{2}\end{array}\end{array}$ & $\begin{array}{l}\text { Ceiling Area } \\
40 \\
\mathrm{~m}^{2}\end{array}$ & $\begin{array}{l}\text { Other Surface Area } \\
4 \\
\mathrm{~m}^{2}\end{array}$ & $\begin{array}{l}\text { Surface to Volume Ratio } \\
1.5\end{array}$ \\
\hline Infiltration & $\begin{array}{l}\text { Infitration } \\
0.5 \\
\end{array}$ & $\begin{array}{l}\text { Particle Penetration Coefficient } \\
1\end{array}$ & & & & \\
\hline Ventilation System & $\begin{array}{l}\text { Supply Airflow Rate } \\
\begin{array}{ll}360 \\
6 m^{2} / h\end{array}\end{array}$ & $\begin{array}{l}\text { Outdoor Air Intake Fraction } \\
0\end{array}$ & $\begin{array}{l}\text { Retum Airflow Rate } \\
\begin{array}{ll}3300 & \mathrm{sm} / \mathrm{h}\end{array}\end{array}$ & $\begin{array}{l}\text { Local Exhaust Airflow Rate } \\
\begin{array}{l}0 \\
\mathrm{sm}^{3} / \mathrm{h}\end{array}\end{array}$ & & \\
\hline System Filters & $\begin{array}{l}\text { Outdoor Air Filter } \\
\begin{array}{|l}\text { None } v \\
\end{array}\end{array}$ & $\begin{array}{l}\text { Recirculation Air Filter } \\
\begin{array}{|l}\text { MERV } 8 \vee \\
\end{array}\end{array}$ & & & & \\
\hline Calculated Airflows & $\begin{array}{l}\text { Total Outdoor Air Change Rate } \\
\begin{array}{|l|l|l}1 / \mathrm{n} & \mathbf{2}\end{array}\end{array}$ & $\begin{array}{l}\text { Outdoor Air Intake Rate } \\
\begin{array}{|l}0 \\
\mathrm{sm} / \mathrm{h}\end{array}\end{array}$ & $\begin{array}{l}\text { Recirculation Airflow Rate } \\
\begin{array}{|ll}360 & \mathrm{sm} / \mathrm{h}\end{array}\end{array}$ & & & \\
\hline Room Air Cleaner & $\begin{array}{l}\text { Maximum Airflow Rate } \\
\begin{array}{ll}200 \\
\text { sccim }\end{array}\end{array}$ & $\begin{array}{l}\text { Fan Flow Fraction } \\
1\end{array}$ & $\begin{array}{l}\text { Filter Efficiency } \\
0.8\end{array}$ & $\begin{array}{l}\text { CADR } \\
160 \\
\text { scfm }\end{array}$ & & \\
\hline Particle Properties & $\begin{array}{l}\text { Name } \\
\begin{array}{|l}\text { N1 } \\
\end{array}\end{array}$ & $\begin{array}{l}\text { Diameter } \\
11\end{array}$ & $g / \mathrm{cm}^{2} v$ & $\begin{array}{l}\text { Particle Deactivation } \\
\begin{array}{l}\text { On } \vee \\
\end{array}\end{array}$ & $\begin{array}{l}\text { Half-life } \\
\begin{array}{|lll}1.1 & \\
\end{array}\end{array}$ & $\begin{array}{l}\text { Decay Rate } \\
0.63014 \\
\end{array}$ \\
\hline Continuous Source & $\begin{array}{l}\text { Source } \\
\text { On } v \\
\end{array}$ & $\begin{array}{l}\text { Generation Rate } \\
3.2\end{array}$ & $\begin{array}{l}\text { Generation Time Period } \\
\text { Start [00:00 / End 24:00 }\end{array}$ & & & \\
\hline Burst Source & $\begin{array}{l}\text { Source } \\
\text { Onv } \\
\end{array}$ & $\begin{array}{l}\text { Burst Type } \\
\text { Intermittent } \mathbf{V}\end{array}$ & $\begin{array}{l}\text { Amount per Burst } \\
45\end{array}$ & $\begin{array}{l}\text { Generation Time Period } \\
\text { Start } 00: 01 / \text { End } 24: 00\end{array}$ & $\begin{array}{l}\text { Burst Interval } \\
10 \text { min }\end{array}$ & \\
\hline $\begin{array}{l}\text { Particle Deposition } \\
\text { Velocities }\end{array}$ & $\begin{array}{l}\text { Floor } \\
0.00371 \\
\end{array}$ & $\begin{array}{l}\text { Walls } \\
0.000326\end{array}$ & $\begin{array}{l}\text { Ceiling } \\
0.0000000433 \mathrm{~cm} / \mathrm{s}\end{array}$ & $\begin{array}{l}\text { Other Surface } \\
0 \mathrm{~cm} / \mathrm{s}\end{array}$ & $\begin{array}{l}\text { Effective Deposition Rate } \\
\begin{array}{ll}.000848 \\
1 / \mathrm{h}\end{array}\end{array}$ & \\
\hline Initial Concentrations & $\begin{array}{l}\text { Outdoor Air } \\
0\end{array}$ & $\begin{array}{l}\text { Zone Air } \\
0\end{array}$ & & & & \\
\hline Occupant Exposure & $\begin{array}{l}\text { Occupancy Time Period } \\
\text { Start [7:00/End } 17: 00\end{array}$ & $\begin{array}{l}\text { Occupancy Type } \\
\text { Intermintent } \mathbf{V}\end{array}$ & $\begin{array}{l}\text { Intermittent Occupancy Interval } \\
\begin{array}{|l|l}00 & \text { min }\end{array}\end{array}$ & $\begin{array}{l}\text { Intermittent Occupancy Duration } \\
\begin{array}{ll}10 & \text { min }\end{array}\end{array}$ & & \\
\hline
\end{tabular}

Version 1.0 - Page Updated : Fri May 222020 - Page Created : 05/2020

Figure 3-FaTIMA web interface (Input section) 
Fate and Transport of Indoor Microbiological Aerosols (FaTIMA)

Instructions: Set Inputs then click the RUN SIMULATION button.

Run smulation Simulation Complete. Project File Download CONTAM Project Report Download CSVReport Go back to inputs

Results

\begin{tabular}{|c|c|c|c|c|c|}
\hline Sources & $\begin{array}{l}\text { Continuous } \\
4008.5\end{array}$ & $\begin{array}{l}\text { Burst } \\
0480.2\end{array}$ & $\begin{array}{l}\text { Outdoor } \\
0\end{array}$ & $\square$ & \\
\hline Airborne Concentration & $\begin{array}{l}\text { Average }(10 \mathrm{~h}) \\
0.01784\end{array}$ & $\begin{array}{l}\text { Average }(24 \mathrm{~h}) \\
0.01148\end{array} \# / \mathrm{m}^{3}$ & Maximum (24h) $=\square$ & & \\
\hline Airbome Exposure & $\begin{array}{l}\text { Average }(10 \mathrm{~h}) \\
0.1528 \mathrm{~m}\end{array}$ & 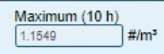 & $\begin{array}{l}\text { Integrated Exposure } \\
5507.4\end{array}$ & & \\
\hline Surface Loading & $\begin{array}{l}\text { Floor } \\
20221 \\
\end{array}$ & $\begin{array}{l}\text { Wals } \\
025876\end{array}$ & $\begin{array}{l}\text { Ceiling } \\
0.00034104\end{array}$ \#/m² $^{2}$ & 0 & $\begin{array}{l}\text { Total } \\
3.1789\end{array}$ \\
\hline Deposited & $\begin{array}{l}\text { Floor } \\
11.88 \\
\end{array}$ & $\begin{array}{l}\text { Walls } \\
10.241\end{array}$ & $\begin{array}{l}\text { Ceiling } \\
0.0013642\end{array}$ & $\begin{array}{l}\text { Other } \\
0\end{array}$ & 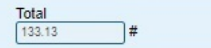 \\
\hline Filtered & Outdoor Air & $\stackrel{\text { Recirculation }}{2459.9}=\#$ & $\begin{array}{l}\text { Air Cleaner } \\
5047.3\end{array}$ & Envelope & $\begin{array}{l}\text { Total } \\
\text { 84072. }\end{array}$ \\
\hline Other & \begin{tabular}{|l|l|} 
Deactivated \\
1378.3
\end{tabular} & $\begin{array}{l}\text { Exited Zone } \\
1003.9\end{array}$ & $\left.\begin{array}{l}\text { Remain Airbome } \\
75.94\end{array}\right]$ & & \\
\hline
\end{tabular}

Transient Charts

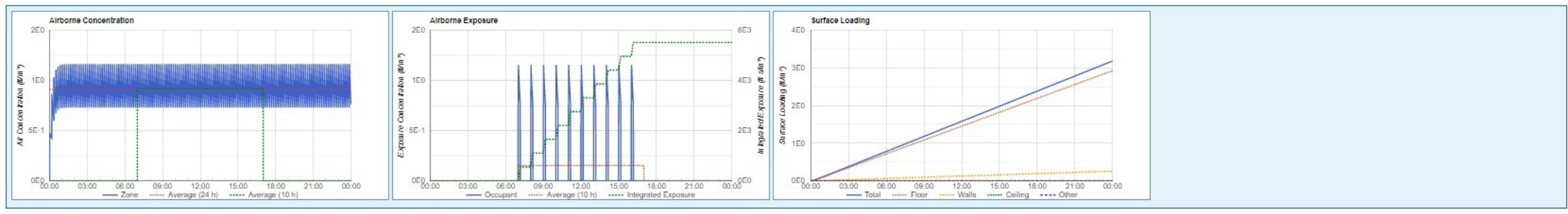

Particle Fate Summary Charts

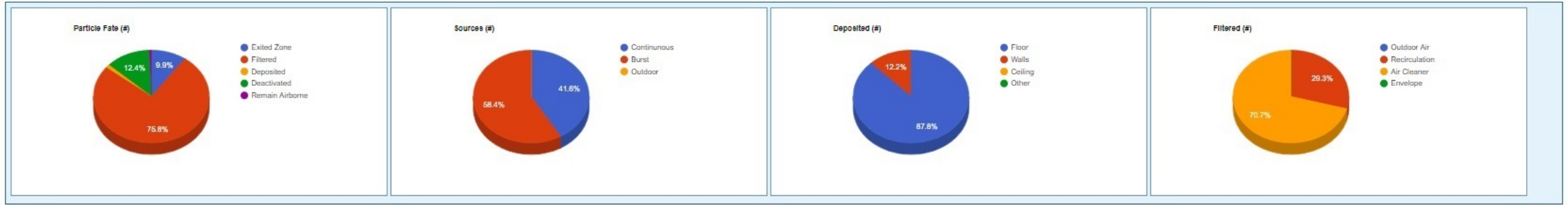

Go back to Inputs

Figure 4-FaTIMA web interface (Results section) 


\subsection{Web-based CONTAM Solver}

The CONTAM program consists of a graphical user interface, referred to as ContamW, and a solver, referred to as ContamX, which is written in the $C$ programming language, and converted to JavaScript to run in a web-based environment [4]. The benefit of this approach is that FaTIMA is running the ContamX solver, that has been well validated [5-8] and is considered by many to be the de facto tool for whole building airflow and indoor air quality analysis. The development process, theory, assumptions, and verification and validation test cases were presented in the documentation of a previously developed web-based tool [9].

Details of the CONTAM solver are provided in the CONTAM User Guide [1]. For the purposes of this tool, ContamX utilizes the web-based, user inputs to establish the ventilation system airflow rates and determine the air balance of the single zone. Once the airflow rates are obtained, ContamX performs a contaminant mass balance as per equations (1) and (2) using an implicit solution method to simultaneously determine the aerosol concentration and surface loadings for each time step over the simulation period. For this tool, the time step is hard coded to 15 seconds and the simulation period to 24 hours.

\section{FaTIMA Modeling Considerations}

The underlying CONTAM software provides a generalized modeling tool that allows users to address a broad range of problems related to contaminant transport within the built environment. FaTIMA is meant to simplify targeting a specific class of problems related to bioaerosols. Therefore, this section is provided for convenience to users of FaTIMA in selecting inputs using previously published information. These inputs are not meant to be recommendations for applying the tool but to help users to become familiar with its capabilities.

Inputs to FaTIMA include properties of the aerosol being simulated. The components of biological aerosols typically consist of droplets or smaller droplet nuclei which contain pathogens, e.g., viruses. The term particle in the following sections refers to the individual components of an aerosol, of user-defined size and density.

\subsection{Zone Geometry}

FaTIMA employs a single zone model, with the zone geometry described by the zone volume and several surface areas. Inputs related to surface areas are labeled Floor, Wall, Ceiling, and Other. These surface areas are provided to account for removal of airborne particles by deposition onto these surfaces. The surface areas defined for the Floor, Wall, and Ceiling category can include surfaces other than those indicated by the labels. For example, one might include all upward facing surfaces in the Floor category, vertical surfaces in the Wall category, and downward facing surfaces in the Ceiling category. In this way, the deposition onto items contained within a zone can be accounted for, e.g., furniture and wall fixtures. The Other category could be used to account for other surfaces or fomites within the zone.

The surface-to-volume ratio is provided for informational purposes. Particle deposition studies have been performed (see Particle Deposition Rates section below) that present surface-to- 
volume ratios for laboratory chamber experiments and field studies with buildings. Hussein, Glytsos, et al. (2006) report surface-to-volume ratios of rooms in a single floor of a residence on the order of 1.5 to 2.5, not including furnishings, and between 2 and 3.3 when accounting for furnishings in the same rooms.

\subsection{Infiltration}

Infiltration refers to air leakage through unintentional openings in the exterior envelope of a building, driven by wind, indoor-outdoor temperature difference and equipment operation. Infiltration is dynamic, varying in time over a range of 5 to 1 or more for a given building [11]. CONTAM calculates infiltration from mass balance principles, but FaTIMA is limited to using a constant value entered by the user. For residential buildings, average infiltration rates are typically between $0.1 \mathrm{~h}^{-1}$ to $1.0 \mathrm{~h}^{-1}$ [12]. Commercial buildings are often assumed to have no infiltration during normal operation of the heating, ventilation, and air-conditioning (HVAC) system though that is rarely true. Past studies have shown that infiltration in commercial buildings can be of the same order of magnitude as mechanical ventilation rates in those buildings [13]. However, newer commercial buildings with an air barrier may be tight enough to significantly reduce infiltration rates [14].

\subsection{Ventilation}

In most existing single-family, residential buildings in the U.S., the HVAC system supply airflow rate is equal to the return airflow rate (neglecting duct leakage) with no outdoor air brought in by the system. While these airflow rates can vary widely, a reasonable airflow rate is on the order of $9.0 \mathrm{~m}^{3} / \mathrm{h} \cdot \mathrm{m}^{2}\left(0.5 \mathrm{cfm} / \mathrm{ft}^{2}\right)$ of floor area. The importance of this airflow rate in FaTIMA is related to the removal of particles as air flows across the recirculation air filter, i.e., for a given filter the higher the airflow rate the more particles will be removed. By default, most residential supply fans cycle on and off based on thermostatic control, but some have a setting for continuous operation. Some newer residential buildings in the U.S. have outdoor air introduced via mechanical ventilation, which may be part of the central heating or cooling system or a separate heat recovery ventilator. The outdoor airflow rates may be designed to meet the requirements of ASHRAE Standard 62.2 [15] and can range from $100 \mathrm{~m}^{3} / \mathrm{h}$ to $200 \mathrm{~m}^{3} / \mathrm{h}$ depending on house size and number of occupants.

Most commercial and institutional buildings have mechanical ventilation systems. Many of those will have design outdoor air ventilation rates intended to meet ASHRAE Standard 62.1 [16]. However, the actual outdoor air intake rates can vary significantly from the design values. The main determinant of design ventilation rates is the occupant density for the space type, and ventilation rates can range from about $0.4 \mathrm{~L} / \mathrm{s} \cdot \mathrm{m}^{2}\left(0.08 \mathrm{cfm} / \mathrm{ft}^{2}\right)$ for less densely occupied spaces such as offices to about 10 times that for more densely occupied spaces like auditoria and classrooms.

\subsection{Particle Filters}

FaTIMA accounts for filtration of particles within the ventilation system, by a room air cleaner and by losses within infiltration pathways of the building envelope (referred to as penetration). Ventilation system filters can be specified according to the minimum efficiency reporting value 
(MERV) [17]. Particle removal efficiency curves for different MERV levels based on work done by Kowalski, Bahnfleth, et al. (1999) are presented in Figure 5. In FaTIMA, the user selects from a predefined set of MERV filters to define the ventilation system filters. It is also important to note that other factors can reduce the effective efficiency of a filtration system, such as airflow that bypasses around a filter.

FaTIMA requires room air filter efficiencies to be defined by the user. Room air cleaners sometimes use high-efficiency particulate air (HEPA) filters that can trap $99.97 \%$ or more of particles that are $0.3 \mu \mathrm{m}$ diameter or larger. Particle filtration efficiencies of HEPA filters are generally higher than a MERV 16 rating. Particle filtration efficiencies for a filter media-based room air cleaner can also be obtained by referring to Figure 5 for the particle size being modeled and the appropriate filter rating.

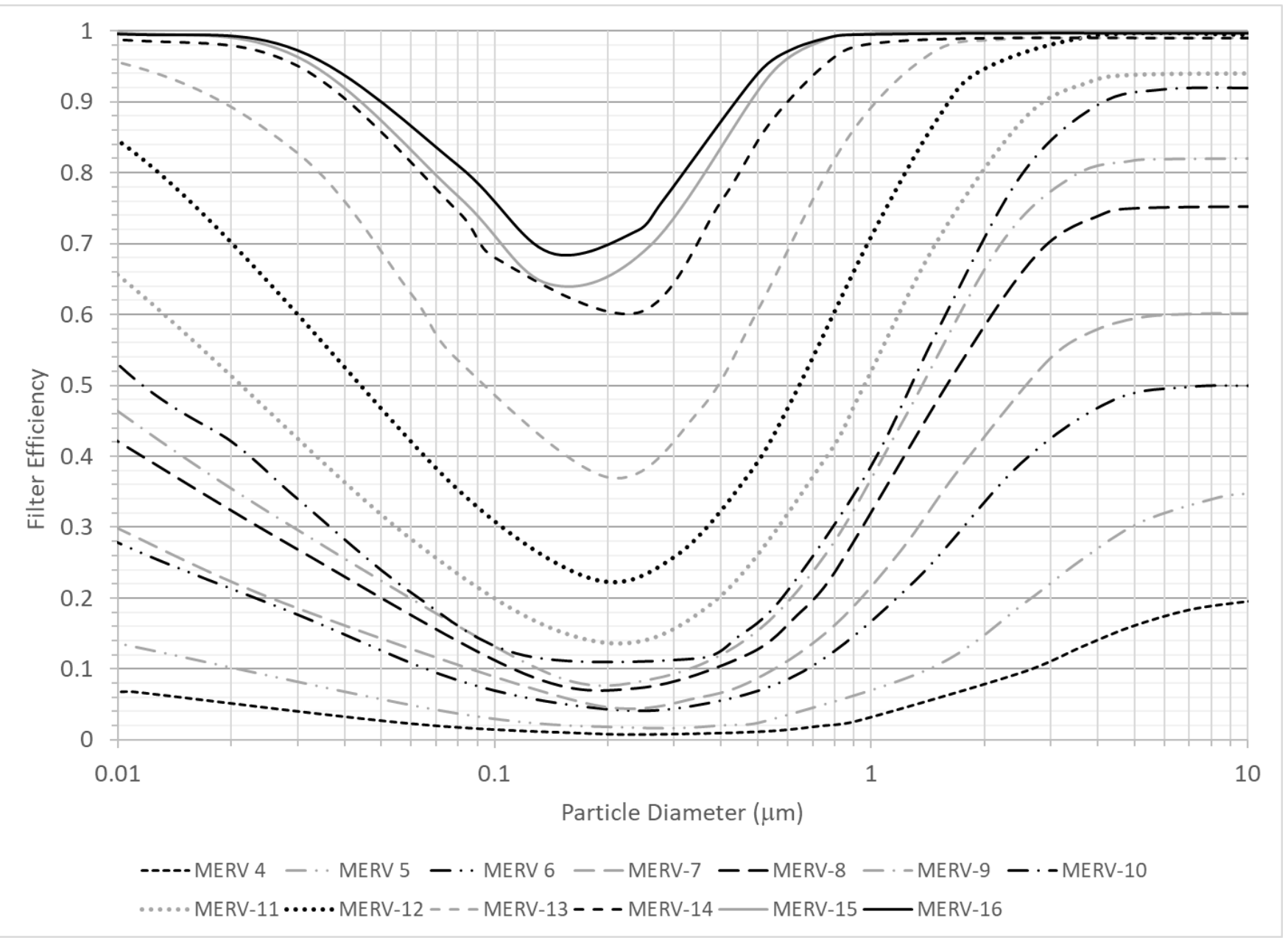

Figure 5 - Chart of particle filtration efficiency vs particle diameter for a range of MERV filter ratings. 


\subsection{Particle Properties and Generation}

The goal of FaTIMA is to determine the fate of microbiological aerosols generated within the built environment. The generation and fate are dependent on the properties of the aerosol being simulated. The user must establish the properties of the aerosol to model including the diameter, density, generation rate, deposition rate, and pathogen deactivation rate.

Aerosols generated by building occupants are generally made up of a range or distribution of particles of varied sizes, shapes, and constituent materials. However, the current version of FaTIMA is limited to consideration of a single, representative size particle in each simulation. Therefore, it is important to understand that results provided by FaTIMA are dependent on input assumptions and modeling strategies. For example, a user could simulate a given particle size within an aerosol distribution or a specific particle size within an aerosol distribution that might contain a viable virus component. The virus (or pathogen) is a small component by mass and volume of a significantly larger particle (droplet nuclei), and FaTIMA would be used to calculate the fate of the virus based upon the physical characteristics of the larger, pathogenladen particle.

The three major characteristics to be considered when preparing to set up a FaTIMA modeling effort include aerosol particle size, generation rate, and viable virus loading.

\subsubsection{Aerosol Size}

Airborne sources of communicable diseases are typically generated by people coughing, sneezing, speaking, and exhaling pathogen-laden bioeffluents. These bioeffluents include aqueous droplets on the order of $10 \mu \mathrm{m}$ or larger and smaller droplet nuclei often considered to be about $5 \mu \mathrm{m}$ or less in diameter [19]. Droplets are relatively large and can fall rather quickly towards the ground due to gravitational settling and can impact various surfaces or directly enter the respiratory tract of another, nearby occupant [2]. The smaller droplet nuclei can remain airborne in the form of aerosols for longer periods of time, and these aerosolized particles are the focus of FaTIMA. The aqueous properties of these aerosols also lead to a typical assumption that the density of the aerosol particles is the same as that of water, which is approximately $1.0 \mathrm{~g} / \mathrm{cm}^{3}$.

\subsubsection{Generation}

FaTIMA provides two types of sources to generate particles within the zone: continuous and burst. Tidal breathing is an example of a continuous source of aerosols from a human occupant. Burst sources such as coughs or sneezes can be modeled using FaTIMA as either single or intermittent. In FaTIMA, all particles generated are instantly diluted to the entire zone volume.

To model particles emitted, the rate of particle generation of the specified aerosol size must be input. To assist in developing this input, users are referred to studies that have been performed to quantify the generation of aerosols that contain pathogens emitted by people infected with various illnesses when breathing, coughing, and sneezing; for example as presented in the following references [20-23]. 


\subsubsection{Viable Virus Loading}

If the modeling strategy involves simulating viable virus-laden aerosols, then the generation rate of the aerosol containing viable viruses must be input. In addition, one may also choose to account for deactivation of viable viruses. FaTIMA provides for the input of a half-life (deactivation rate) to enable tracking particles that contain viable viruses that have been deactivated during the simulation. In FaTIMA, deactivated particles are removed from the air; therefore, they do not accumulate on surfaces, get removed by filters, or count towards occupant exposure.

\subsection{Particle Deposition Rates}

Particle deposition rates have been measured within various environments including occupied spaces and test chambers [24, 25]. Models of deposition velocity and rates have also been developed, and one such model is presented here based on the work of Lai and Nazaroff (2000). This deposition velocity model was developed for deposition onto smooth surfaces as a function of friction velocity and enclosure geometry. The friction velocity represents the effects of indoor airflow intensity and its determination is the most uncertain aspect of selecting deposition velocities. Note that relatively higher values are associated with measurements performed in building environments as opposed to test chambers [27]. These measurements performed in buildings have shown that more accurate model results are obtained using friction velocities of $0.1 \mathrm{~m} / \mathrm{s}$ or greater.

FaTIMA requires entering deposition velocities for the modeled particle size. Deposition velocities for upward facing (floors), vertical (walls), and downward facing (ceilings) surfaces are presented based on the Lai and Nazaroff (2000) model in Figure 6 through Figure 8 for a particle density of $1.0 \mathrm{~g} / \mathrm{cm}^{3}$ over a range of friction velocities. Deposition velocities for other particle densities and size ranges can be calculated using the size-resolved modeling tool previously developed by NIST [4]. Figure 6 also provides the particle settling velocity for upward facing surfaces. Other models have been developed for rough surfaces within ventilation ducts, which tend to lead to higher deposition rates mainly for smaller sized particles, i.e., less than $1 \mu \mathrm{m}$ in diameter [27]. If the modeled particle size is changed, the deposition velocities must also be changed accordingly.

FaTIMA provides an Effective Deposition Rate based on the combination of all the deposition velocities and surface areas entered for a given simulation (see equation (10) in the FaTIMA User Guide section). For comparative reference to the Effective Deposition Rate in FaTIMA, measurements of deposition velocities from the work of Reed, Wallace, et al. (2003) are presented in Figure 10. They reported deposition rates of various size particles (generated by cooking, burning candles, and pouring kitty litter) within an occupied townhouse and an unoccupied test house with three different ventilation system configurations: fan off, fan on, and fan on with an electrostatic precipitation filter operating. 


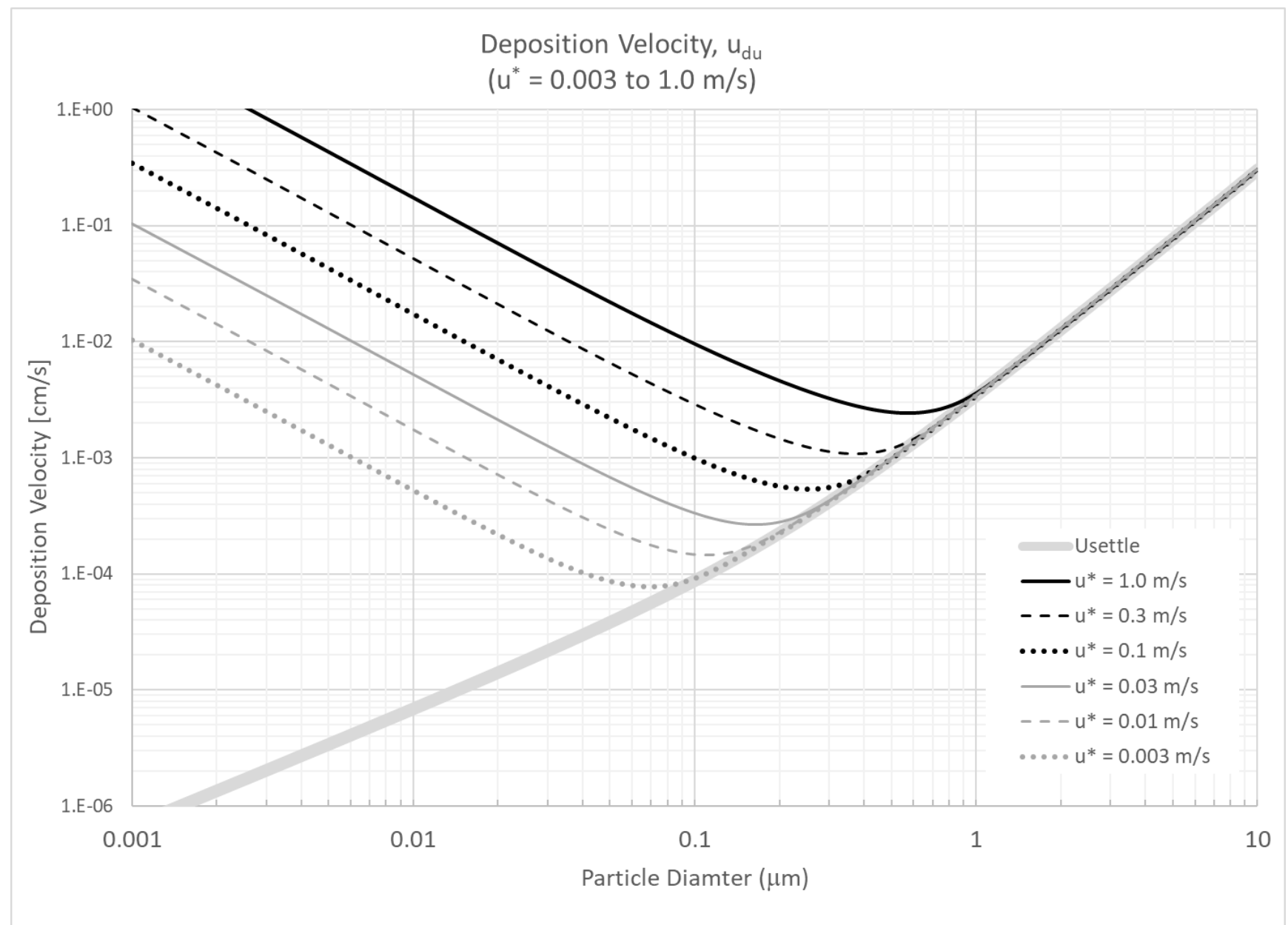

Figure 6 - Particle settling velocity and deposition velocities for upward facing surfaces $\left(u_{d u}\right)$ based on Lai and Nazaroff deposition model over a range of friction velocities, $u^{*}$, and particle density of $1.0 \mathrm{~g} / \mathrm{cm}^{3}$. 


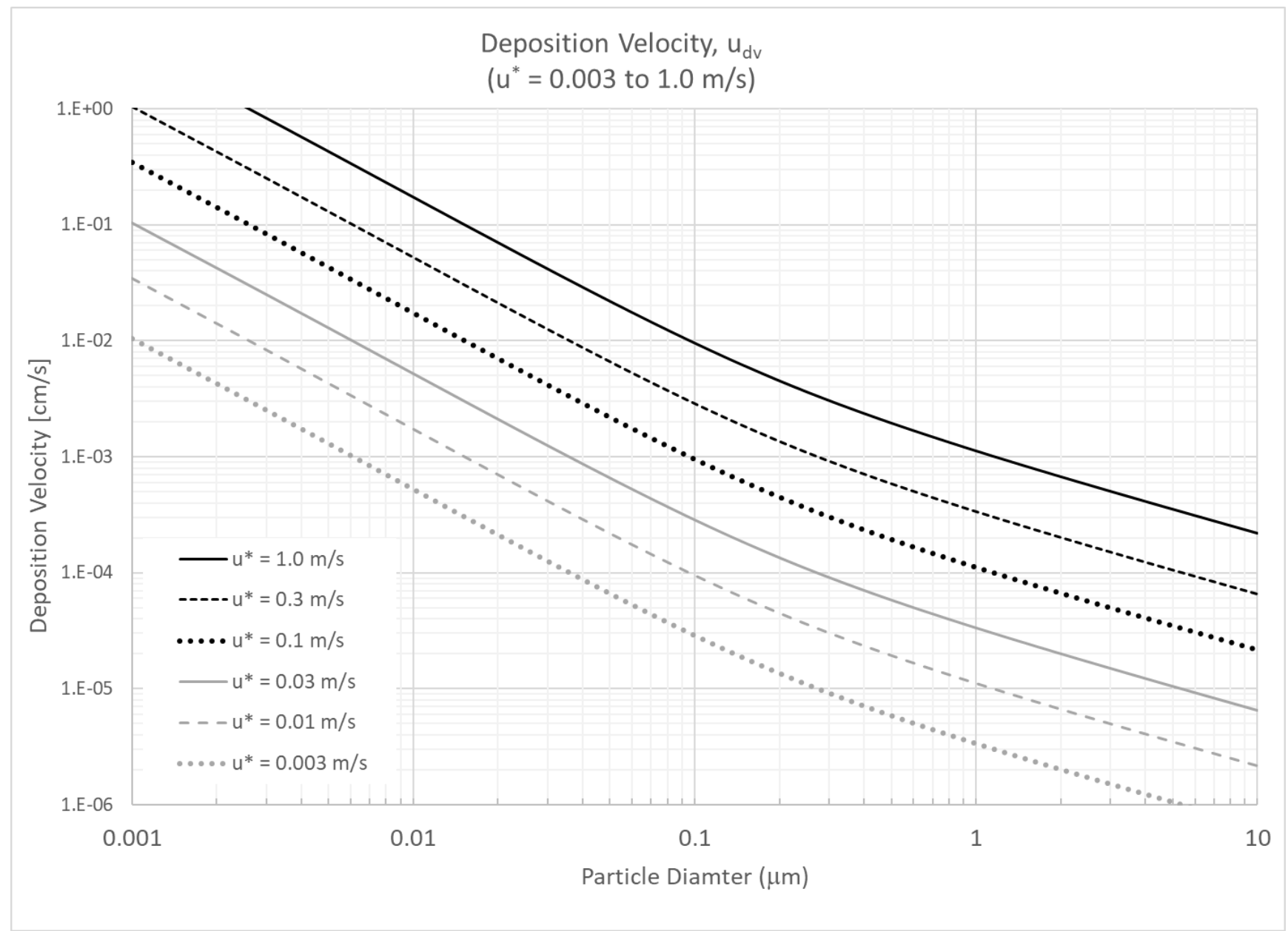

Figure 7 - Particle deposition velocities for vertical surfaces $\left(u_{d v}\right)$ based on Lai and Nazaroff deposition model over a range of friction velocities, $u^{*}$, and particle density of $1.0 \mathrm{~g} / \mathrm{cm}^{3}$. 


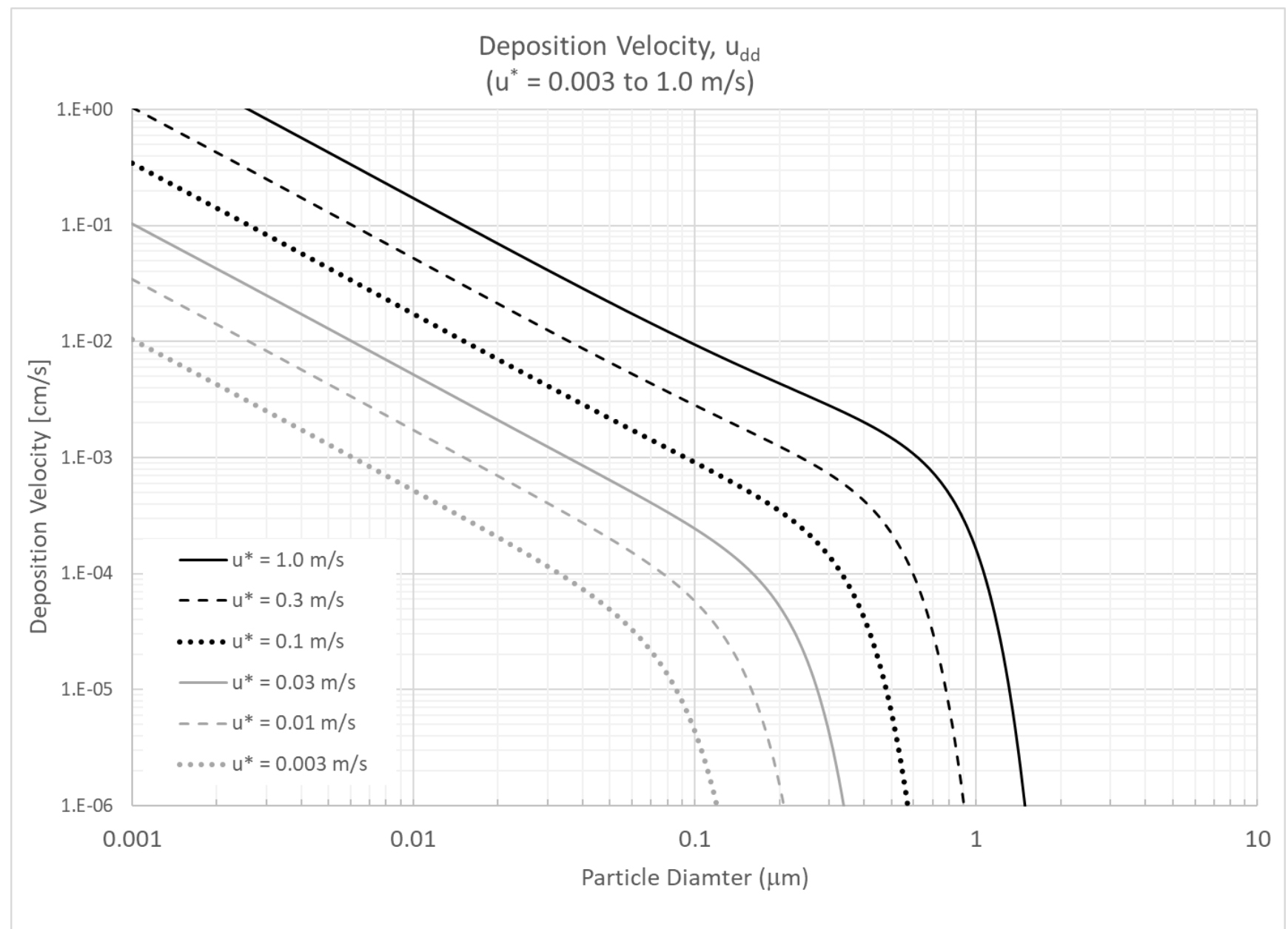

Figure 8 - Particle deposition velocities for downward facing surfaces $\left(u_{d d}\right)$ based on Lai and Nazaroff deposition model over a range of friction velocities, $u^{*}$, and particle density of $1.0 \mathrm{~g} / \mathrm{cm}^{3}$. 


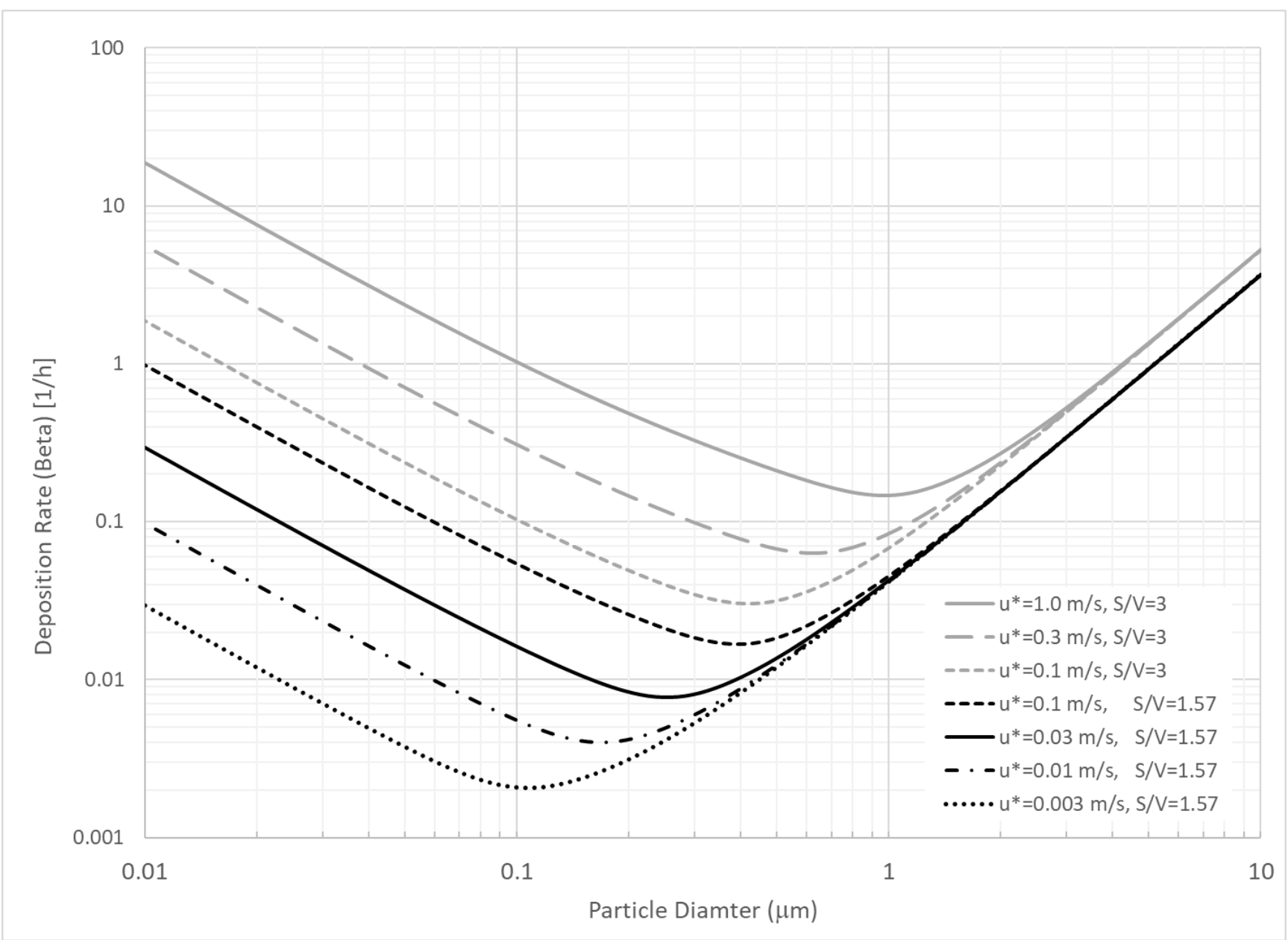

Figure 9 - Deposition rates ( $\beta$ ) calculated based on the Lai and Nazaroff deposition model for two surface to volume ratios $(S / V)$ over a range of friction velocities $\left(u^{*}\right)$, and particle density of $1.0 \mathrm{~g} / \mathrm{cm}^{3}$. 


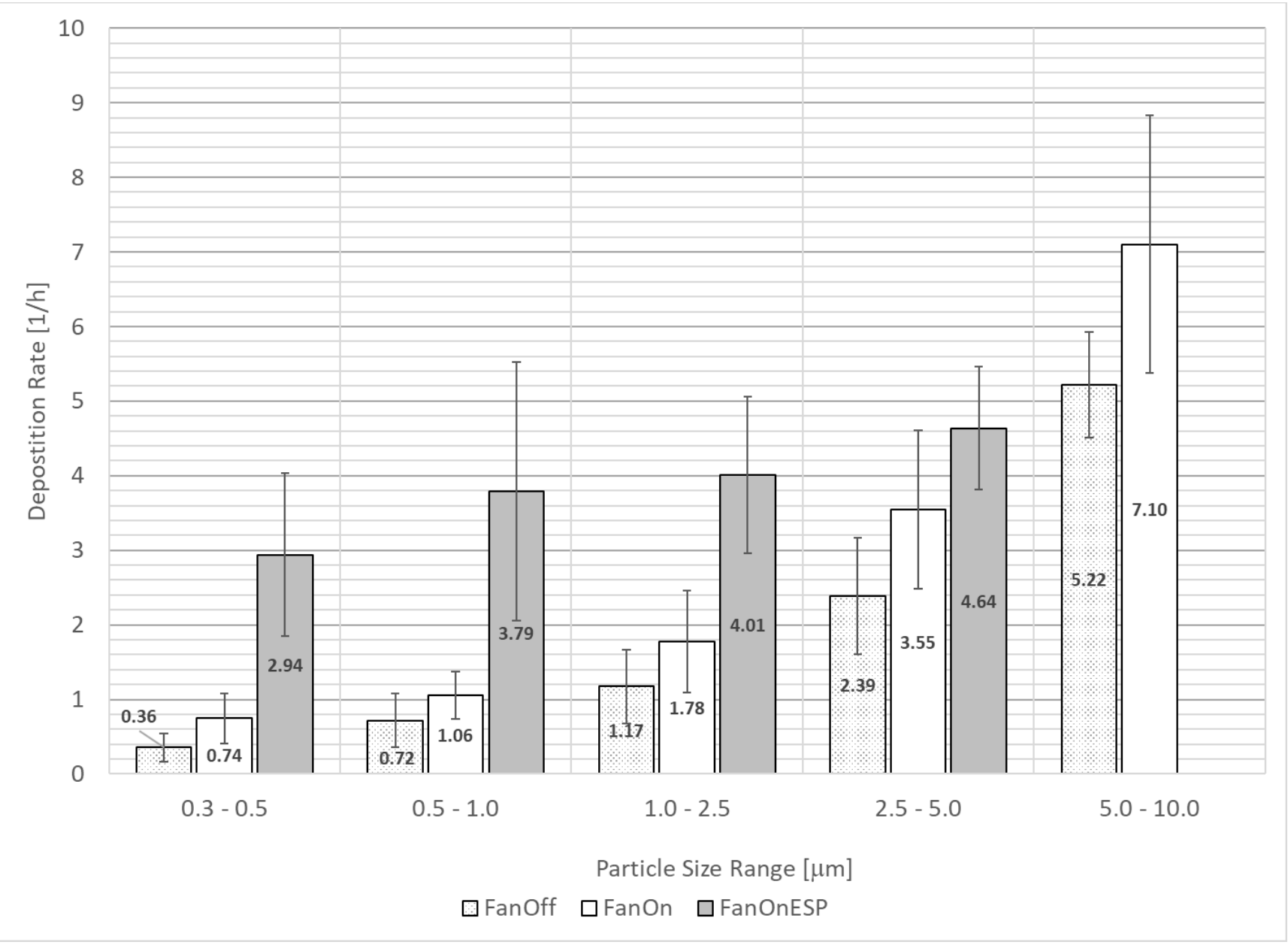

Figure 10 - Average particle deposition rates with error bars showing standard deviation based on measurements in an occupied townhouse with HVAC system fan off, fan on, and fan on with an electrostatic precipitator (ESP) [28].

\subsection{Particle Penetration Coefficients}

Particle penetration refers to the entry of particles into a building via leaks in the building enclosure or envelope. This parameter is included in FaTIMA when consideration of outdoor particle sources is of concern. Particle penetration is not generally relevant when analyzing the spread of occupant-generated microbiological aerosols unless there are significant concentrations of outdoor particles of the same size as the indoor-generated particles, or if it is assumed there is a "significant" source of outdoor microbiological particles that could infiltrate through the building envelope.

One means of describing the loss of particles through the building envelope is by particle penetration coefficients, which are measures of the ability of particles to pass through the building envelope, or conversely, to be filtered as they pass through. Penetration coefficients relate to particle removal efficiency according to the following equation:

$$
P=1-\eta_{\text {eff }}
$$


There have been many studies of the penetration of particles into the built environment. These studies mostly involve the measurement of outdoor particle concentrations, whole building air change rates and fitting the results of various experimental configurations to equations that account for the various particle removal mechanisms involved. Three such studies provide measurements of both penetration and deposition rates in multiple homes [29-31].

Measurements tend to vary widely and depend on many factors including particle diameter, building construction and configuration, testing conditions, e.g., wind and indoor-outdoor temperature difference, and measurement techniques. Emmerich and Nabinger (2001) measured penetration coefficients in a single room test house as presented in Table 1 [32].

Table 1 - Particle penetration coefficients measured in a single room test house.

\begin{tabular}{|c|c|c|c|c|}
\hline \multirow{2}{*}{} & \multicolumn{4}{|c|}{ Particle Penetration Coefficients [-] } \\
\cline { 2 - 5 } & $\mathbf{0 . 3}$ to $\mathbf{0 . 5} \boldsymbol{\mu m}$ & $\mathbf{0 . 5}$ to $\mathbf{0 . 7} \boldsymbol{\mu m}$ & $\mathbf{0 . 7}$ to $1.0 \mu \mathrm{m}$ & $\mathbf{1 . 0}$ to $\mathbf{5 . 0} \boldsymbol{\mu m}$ \\
\hline Average & 0.76 & 0.73 & 0.66 & 0.60 \\
\hline Std Dev & 0.27 & 0.15 & 0.08 & 0.09 \\
\hline
\end{tabular}




\section{FaTIMA User Guide}

This user guide provides detailed information on the inputs and outputs of FaTIMA. Variable names reflect those provided in Equations (1) and (2) and Figure 1. Most inputs can be entered in a variety of user selectable units.

\section{Inputs}

Inputs define the zone and ventilation system properties, particle source and removal mechanisms, and the occupant exposure period.

\section{Zone Geometry}

Volume: Set the volume $(V)$ and unit.

Floor, Wall, Ceiling, and Other Surface Area: Set the areas $\left(A_{s i}\right)$ and unit for those surfaces onto which deposition occurs. Other Surface Area can be used to account for any atypical deposition surfaces not accounted for by the first three categories, for example other fomites within the zone onto which particles might deposit. The Floor Area unit selection applies to all entered areas.

Note: Surface areas are utilized in the model to account for deposition of particles onto the surfaces. Inputs related to the deposition velocities are provided in the section titled FaTIMA Modeling Considerations and are specified according to the orientation of the deposition surfaces. While the surfaces are labeled Floor, Wall, and Ceiling, the areas can also include other surfaces having the same orientation (or associated deposition velocity), e.g., the surfaces of table and desks could also be included in the Floor area.

\section{Infiltration}

Infiltration: Set the infiltration rate $\left(Q_{i n f}\right)$ in units of $\mathrm{h}^{-1}$. This infiltration rate will be in addition to infiltration that might occur due to an imbalance in system airflow rates as described in the Ventilation System section.

Particle Penetration Coefficient: Set the penetration coefficient $(P)$ to account for filtration of particles as they enter through the building envelope. This will only have an effect if the outdoor concentration is greater than zero and infiltration is defined by the user and/or occurs due to an imbalance between the supply and return airflow rates.

Note: A value of 1 means that all the particles will penetrate the building envelope from outdoors, while a value of 0 means that none of the particles will enter the zone from the outdoors via the building envelope.

\section{Ventilation System}

Supply Airflow Rate and Return Airflow Rate: Set the supply airflow rate $\left(Q_{S}\right)$ and return airflow rate $\left(Q_{r}\right)$ of the air handling system and associated units. The Supply Airflow unit selection applies to all entered airflow rates.

Outdoor Air Intake Fraction: Set the fraction of outdoor air $\left(Q_{o a} / Q_{S}\right)$ of the simple air handling system to a value between 0 and 1 . This must be less than 1 for zone air to be recirculated through the simple air handling system. 
Local Exhaust Airflow Rate: Set the local exhaust airflow rate $\left(Q_{I_{X}}\right)$ to remove air directly from the zone to the outdoors. This exhaust will be in addition to any air exhausted via the ventilation system, i.e., AHS. Examples of local exhaust include kitchen and bathroom exhaust fans and clothes dryers.

\section{System Filters}

Outdoor and Recirculation Air Filter: Select the filters from the list of Minimum Efficiency Reporting Values (MERV) to include within the outdoor and/or recirculation air streams of the simple air handling system (see Figure 1).

Note: Not all filters are provided with a MERV rating. However, Figure 5 can be used to select a MERV filter based on a known filtration efficiency for the size of particle being simulated.

\section{Calculated Airflows}

Total Outdoor Air Change Rate: Calculated from the previous inputs for informational purposes. All airflow calculations are performed in the base units of mass flow rate $(\mathrm{kg} / \mathrm{s})$ with a density of $1.2041 \mathrm{~kg} / \mathrm{m}^{3}$. The calculation presented in equations (4) through (7) are based on units of $\mathrm{m}^{3} / \mathrm{h}$ for volumetric airflow rates and volume in $\mathrm{m}^{3}$.

$$
\text { Air change rate }=\left[Q_{\text {inf }}+Q_{o a}-\operatorname{Min}\left(0.0, Q_{b a l}\right)\right] / V
$$

where

$$
Q_{b a l}=Q_{s}+Q_{i n f}-Q_{r}-Q_{l x}
$$

The zone air balance, $Q_{b a l}$, provides an indication of whether the zone is positively, negatively or neutrally pressurized. If the value is negative, then the air change rate is increased beyond that attributed to outdoor air intake by the ventilation system and the specified infiltration.

Outdoor Airflow Rate: Calculated from the previous inputs for informational purposes. It is the amount of outdoor air brought into the zone via the ventilation system, i.e., the simple air handling system $\left(Q_{o a}\right)$.

Recirculation Airflow Rate: Calculated from the previous inputs for informational purposes. It is the amount of return air recirculated back into the zone via the Ventilation System $\left(Q_{\text {rec }}\right)$. If $Q_{\text {rec }}$ is greater than zero, then zone air can be filtered prior to being mixed into the supply air. The airflow rate across the recirculation air filter is calculated as:

$$
Q_{\text {rec }}=\operatorname{Min}\left[Q_{\text {ret }}, Q_{\text {sup }}(1.0-\% O A)\right]
$$

\section{Room Air Cleaner}

Maximum Fan Airflow Rate: Set the maximum airflow rate $\left(Q_{f a n}\right)$ and units for the Room Air Cleaner fan.

Fan Flow Fraction: Set the fraction of the maximum airflow rate $\left(f_{f a n}\right)$ at which the fan is to operate (0 to 1 ). The fan flow setting is provided to account for room air cleaners that have multiple settings for the airflow rate through them. 
Filter Efficiency: Set the particle removal efficiency $\left(\eta_{a c}\right)$ for the diameter of particle being simulated. Filter efficiencies can be obtained from MERV efficiency curves (see Figure 5).

CADR: The Clean Air Delivery Rate is calculated for informational purposes.

$$
\mathrm{CADR}=\eta_{a c} \cdot f_{\text {fan }} \cdot Q_{\text {fan }}
$$

Note: This calculation may not match the CADR provided by the manufacturer for a specific room air cleaner due to assumptions used within the air cleaner testing standard when calculating these values [33]. The test procedure utilizes a standard size room, three types of test particles (smoke, dust, and pollen) and measures the difference in particle removal rates with and without the air cleaner operating. The particle size ranges used in the test procedure are for cigarette smoke $(0.09 \mu \mathrm{m}$ to $1.0 \mu \mathrm{m})$, Arizona road dust $(0.5 \mu \mathrm{m}$ to $3.0 \mu \mathrm{m})$ and Paper Mulberry pollen $(0.9 \mu \mathrm{m}$ to $11 \mu \mathrm{m})$.

\section{Particle Properties}

Name: Set the Name you would like to use to identify the particle. The name is provided for bookkeeping purposes only and saved to the CONTAM project file.

Diameter: Set the Particle Diameter and unit. This value is used to convert between particle number units and mass units, and to establish MERV filter removal rates.

Note: Changing the particle diameter does not automatically update the Particle Deposition Velocities below. Deposition velocities must be updated manually. See the subsection titled Particle Deposition Rates in the FaTIMA Modeling Considerations section. However, particle filtration efficiencies of MERV filters are determined from the particle size entered here.

Density: Set the Particle Density and units. This value is used for unit conversion of particle concentrations.

Note: Particle Deposition velocities and rates provided in Figure 6 through Figure 9 are based on a particle density of $1.0 \mathrm{~g} / \mathrm{cm}^{3}$. Deposition velocities for densities other than $1.0 \mathrm{~g} / \mathrm{cm}^{3} \mathrm{can}$ be obtained using a size-resolved particle modeling tool previously developed by NIST [4]. Deposition rates of smaller particles (dominated by diffusion) are not affected by density, but those of larger particles (dominated by gravitational forces) are proportional to density.

Particle Deactivation: Select either "On" or "Off" to account for removal of particles by deactivation. Only use particle deactivation if modeling only particles that contain viable pathogens, because all particles will be subjected to the deactivation rate.

Half-life: If Particle Deactivation is selected, set the Half-life $\left(\tau_{1 / 2}\right)$ for removal of particles and unit. A Decay Rate ( $\lambda$ ) will be calculated based on the Half-life and utilized to account for deactivation during the simulation.

$$
\lambda=-\ln (0.5) / \tau_{1 / 2}
$$

Note: Particle Deactivation should only be utilized if all particles being simulated are assumed to contain viable pathogens.

Continuous Source

Source: Select to turn the Continuous source "On" or "Off." 
Generation Rate: Set the emission rate for the Continuous source. The units can be particle mass per time or particle number per time. The generation rate $(G)$ is constant during the associated Source Time Period. A continuous source could be used to simulate emission of particles attributed to breathing of an occupant within the zone.

Generation Time Period: Set the Start and End times for particle generation by the Continuous source.

\section{Burst Source}

Source: Select to turn the Burst source "On" or "Off."

Burst Type: Select whether the Burst source should be either a "Single" one-time release or an "Intermittent" release.

Amount per Burst: Set the quantity of particles that each Burst is to contribute to the particle generation rate $(G)$. The units can be particle mass or number of particles. The amount will be released for each burst during a single simulation time step which is hard coded to $15 \mathrm{~s}$.

Generation Time Period: Set the Start and End times for particle generation by the Burst source. If a "Single" burst is selected, then it will be initiated at the Start time (the End time will be greyed out). If an "Intermittent" burst is selected, then particles will be released into the air during this time period at the selected Burst Interval.

Burst Interval: Set the amount of time between intermittent Burst releases. The minimum interval (30 s) is twice that of the simulation time step (15 s).

Note: The Burst source could be used to simulate the emission of particles associated with single or repetitive sneezes or coughs. For example, a single sneeze could be defined to occur by selecting a "Single" Burst Type and a desired Start time. A periodic coughing episode could be defined to occur for one hour at midday by selecting the "Intermittent" Burst Type, setting the Start and End times to 12:00 and 13:00, and setting the interval to 5 min which will result in 12 individual releases during the hour.

\section{Particle Deposition Velocities}

Floor, Walls, Ceiling, and Other Surfaces: Set the Deposition Velocity $\left(v_{d i}\right)$ for each category of surface onto which to account for particle deposition, i.e., removal of particles from the air by deposition. (Set the associated surface areas in the Zone Geometry section.)

Note: Use the following relationship to convert between deposition rate $\left(k_{d i}\right)$ and deposition velocity $\left(v_{d i}\right)$ :

$$
v_{d i}=k_{d i} \frac{V}{A_{s i}}
$$

Effective Deposition Rate: This calculated value is provided for informational purposes and is based on the Deposition Velocities as follows:

$$
k_{\text {eff }}=\frac{v_{d_{-} \text {Floor }} A_{\text {Floor }}+v_{d_{-} \text {Walls }} A_{\text {Walls }}+v_{d_{-} \text {Ceil }} A_{\text {Ceil }}+v_{d_{-} \text {other }} A_{\text {Other }}}{V}
$$

Note: $k_{\text {eff }}$ does not include the Particle Deactivation rate. The Effective Deposition Rate can be compared to deposition rates provided in Figure 9 which provide deposition rates based 
on the deposition model of Lai and Nazaroff (2000) and Figure 10 which provides deposition rates measured in a U.S. townhouse as reported in Howard-Reed, Wallace, et al. (2003).

\section{Initial Concentrations}

Outdoor Air: Set the concentration of the Outdoor Air $\left(C_{o a}\right)$ and units to account for particles entering the zone from the outdoors via the ventilation system and/or infiltration through the building envelope. This concentration will remain constant for the entire simulation period.

Zone Air: Set the initial concentration of the Zone Air to account for particles within the zone air at the beginning of the simulation.

\section{Occupant Exposure}

Occupancy Time Period: Set the Start and End time for the period during which an occupant is to be located within the zone. This time interval will be used to determine the Integrated Exposure.

Note: The occupant is not necessarily the same as that being considered the source of emissions associated with the Continuous and/or Burst source inputs. For example, the source of emissions could be associated with one or more infected individuals within a room, and the exposure could be that of a caregiver or uninfected occupant within the room.

Occupancy Type: Set the occupancy type to be either "Continuous" or "Intermittent". Continuous occupancy indicates that an occupant is to remain in the zone during the entire Occupancy Time Period, and Intermittent indicates the occupant will move into and out of the zone multiple times during the Occupancy Time Period.

Note: An intermittent schedule could be used to reflect a caregiver checking on a patient over the course of the occupancy period for a regular amount of time at regularly spaced intervals.

Intermittent Occupancy Interval: Set the interval at which the occupant is to enter the zone during the Occupancy Time Period for the Intermittent Occupancy Type.

Intermittent Occupancy Duration: Set the duration for which the occupant will remain in the zone during each Intermittent Occupancy Interval. The Intermittent Occupancy Duration must be less than the Intermittent Occupancy Interval.

\section{RUN SIMULATION}

Click the RUN SIMULATION button to perform a 24-hour simulation using the defined inputs. Once this button is clicked, the Inputs section will become hidden, and a notice will appear next to the RUN SIMULATION button indicating the simulation is running. Once the simulation is complete, the Results section will be revealed, and a "Simulation Complete" notification will be displayed along with a "Download CONTAM Project" link. This link allows a CONTAM project (PRJ) file to be saved to the local file system. This PRJ file can be opened using ContamW for further analysis or recordkeeping. Click the "Download CSV Report" link to obtain a commaseparated value file that provides the inputs and results that can be used for recordkeeping. 


\section{Results}

This section provides the results of the most recent set of Input values. Click the Go back to Inputs button to modify the inputs and run another simulation. If the particle size is modified, the deposition velocities will also need to be updated.

\section{Sources}

Continuous: This is the total mass or number of particles generated by the Continuous source for the entire simulation period.

Burst: This is the total mass or number of particles generated by the Burst source for the entire simulation period.

Outdoor: This is the mass or number of particles that enter from the outdoors for the entire simulation period. It includes particles that enter via the outdoor air intake of the Ventilation System and those that enter via the building envelope. Particles that are removed by the outdoor air filter and that are prevented from penetrating the envelope are included in this value.

Total: This is the sum of the previous three values. Use the associated unit box to display source values in different units. This box also controls the units of the Deposited and Filtered results as well as the Particle Fate pie charts below.

\section{Airborne Concentration}

Average and Maximum: These are the average zone air concentrations during the specified occupant exposure period and the entire 24-hour simulation period ( $24 \mathrm{~h}$ ), and the maximum concentration during the entire 24-hour period. Use the associated unit box to convert these values and those of the Airborne Concentration chart below to other units.

\section{Airborne Exposure}

Average and Maximum: These are the average and maximum airborne concentrations to which the occupant is exposed during the Occupancy Time Period. If intermittent exposure is selected, the concentration the occupant breathes when not present in the simulated zone is assumed to be zero.

Note: The concentration to which the occupant is exposed is based on the average aerosol concentration in the zone and does not account for exposure that might occur due to more direct droplet transmission from a cough or sneeze.

Integrated Exposure: This is the integral of the zone air concentration to which the occupant is exposed during the exposure period as reflected by either the Continuous or Intermittent exposure schedule. Use the unit box to convert the integrated exposure value and associated Integrated Exposure chart to other units.

$$
\text { Integrated Exposure }=\int_{t_{\text {start }}}^{t_{\text {end }}} C_{z}(t) d t
$$

Note: Integrated exposure does not account for the occupant inhalation or body uptake rates nor does it account for particle removal due to the presence of an occupant. Such 
considerations could be applied using the downloaded project file to run CONTAM simulations and accessing the resultant simulation output files or by applying a dosage relationship to the integrated value.

\section{Surface Loading}

Floor, Walls, Ceiling, and Other: These are the resultant masses or number of particles deposited on each of the surface types divided by their respective surface areas as defined in the Zone Geometry section. Use the unit box next to Total to convert these values and the Surface Loading chart to other units.

\section{Deposited}

Floor, Walls, Ceiling, and Other: These are the resultant masses or number of particles deposited on each of the surface types for the respective surface areas defined in the Zone Geometry section. The units are controlled via the Sources results unit selection.

\section{Filtered}

Outdoor Air, Recirculation, Air Cleaner, Envelope, and Total: These are the resultant masses of particles removed by each of the filters defined in the System Filters and Room Air Cleaner sections. The total removed by all the filtering mechanisms includes those prevented from entering via the building envelope, i.e., not allowed to penetrate. The filtered units are controlled via the Sources results unit selection.

\section{Other}

Deactivated, Exited Zone, and Remain Airborne: These are the particles that were removed by deactivation or exited the zone either via the ventilation system, local exhaust or through the building envelope depending on the zone air balance. The mass or number of particles that Remain Airborne is calculated as the product of the final zone air concentration and the zone volume.

\section{Transient Charts}

This section provides charts that show the time histories of the simulation results.

Airborne Concentration: This chart shows the time history and the Average Concentration of the zone air for the entire 24-hour simulation period and the occupant exposure period.

The units of the chart are controlled by the Airborne Concentration unit box in the Results section.

Airborne Exposure: This chart shows the airborne zone concentration that reflects the occupant exposure schedule. Occupant is the time history of the zone air concentration when the occupant is in the zone. The Average plot is the average concentration the occupant breathes during the occupancy period. If an "Intermittent" Occupancy Type was simulated, the concentration the occupant breathes when not present in the simulated zone is assumed to be zero. Integrated Exposure presents the cumulative exposure attributed to the time integration of the occupant concentration. The first two items are plotted against the left axis, and the Integrated Exposure is plotted against the right axis. 
The units of the chart are controlled by the Airborne Concentration unit box and the Integrated Exposure unit box provided in the associated Results sections.

Surface Loading: This chart shows the time history of the mass accumulated per unit area of each surface type (floor, walls, ceiling, and other) for the entire 24-hour simulation period.

The units of the chart are controlled by the Surface Loading unit box in the Results section.

\section{Particle Fate Summary Charts}

This section presents a summary of the Results section in the form of pie charts that reflect percentages of particle fate with respect to total values for each category.

The units of these charts are controlled by the unit box in the Sources subsection of the Results section.

Particle Fate: This chart provides an overall summary of the fate of particles. It presents the percentage of the mass of particles that Exited the Zone, the total mass Filtered, the total mass Deposited on surfaces, the mass of particles Deactivated, and the mass of particles that Remain Airborne within the zone.

Sources: This chart shows the percentage of the total mass of particles added to the zone for each of the particle sources.

Deposited: This chart shows the percentage of the total mass of particles that deposited on all the surfaces for each of the surface types.

Filtered: This chart shows the percentage of the total mass of particles removed by the air filters and prevented from entering the building based on the particle penetration coefficient.

\section{Conclusions}

FaTIMA was developed for the purpose of evaluating the impact of building and ventilation system parameters on exposure to indoor microbiological aerosols. It implements a uniform concentration, single zone model. A web-based front-end was developed to a JavaScript version of simulation engine of CONTAM, ContamX. This web-based tool runs as a client-side application within a web browser. The development process, theory, assumptions, and verification and validation test cases were presented in the documentation of a previously developed web-based tool [9]. The current document serves mainly as a user guide for FaTIMA with a section that provides modeling considerations to help inform the user when working with FaTIMA. 


\section{References}

1. Dols, W.S. and B.J. Polidoro, CONTAM User Guide and Program Documentation, NIST Technical Note 1887. 2015, National Institute of Standards and Technology: Gaithersburg, MD.

2. Zhu, S., S. Kato, and J.-H. Yang, Study on transport characteristics of saliva droplets produced by coughing in a calm indoor environment. Building and Environment, 2006. 41(12): p. 1691-1702.

3. Wong, B.C.K., N. Lee, Y. Li, P.K.S. Chan, H. Qiu, Z. Luo, R.W.M. Lai, K.L.K. Ngai, D.S.C. Hui, K.W. Choi, and I.T.S. Yu, Possible Role of Aerosol Transmission in a Hospital Outbreak of Influenza. Clinical Infectious Diseases, 2010. 51(10): p. 1176-1183.

4. Dols, W.S., A.K. Persily, and B.J. Polidoro, Development of Airborne Nanoparticle Exposure Modeling Tools, TN 2004. 2018, National Institute of Standards and Technology: Gaithersburg, MD USA.

5. Emmerich, S.J., Validation of Multizone IAQ Modeling of Residential-scale Buildings: A Review. ASHRAE Transactions, 2001. 107(2).

6. Emmerich, S.J., Validation of CONTAMW Predictions for Tracer Gas in a Townhouse., in Building Simulation 2003, 8th International Building Performance Simulation Association (IBPSA) Conference. Proceedings. 2003, IBPSA: Eindhoven, Netherlands.

7. Dols, W.S., A.K. Persily, and J.B. Morrow, Model Development and Validation for Particle Release Experiments in a Two-story Office Building, TN-1703. 2011, National Institute of Standards and Technology: Gaithersburg.

8. Poppendieck, D., S. Khurshid, W.S. Dols, L.C. Ng, B.J. Polidoro, and S.J. Emmerich, Formaldehyde Concentrations in a Net-Zero Energy House: Real-time Monitoring and Simulation, in Indoor Air 2016. 2016: Ghent, Belgium.

9. Dols, W.S., B.J. Polidoro, and A.K. Persily, Development of Airborne Nanoparticle Exposure Modeling Tools, TN-2004. 2019, National Institute of Standards and Technology: Gaithersburg.

10. Hussein, T., T. Glytsos, J. Ondráček, P. Dohányosová, V. Ždímal, K. Hämeri, M. Lazaridis, J. Smolík, and M. Kulmala, Particle size characterization and emission rates during indoor activities in a house. Atmospheric Environment, 2006. 40(23): p. 4285-4307.

11. Persily, A.K., Field measurement of ventilation rates. Indoor Air, 2016. 26(1): p. 97-111.

12. Persily, A., A. Musser, and S.J. Emmerich, Modeled infiltration rate distributions for US housing. Indoor Air, 2010. 20(6): p. 473-485.

13. Grot, R.A. and A.K. Persily, Measured air infiltration and ventilation rates in eight large office buildings, in Measured air leakage of buildings. 1986, ASTM International.

14. Emmerich, S.J. and A.K. Persily, Analysis of U.S. Commercial Building Envelope Air Leakage Database to Support Sustainable Building Design. International Journal of Ventilation, 2014. 12(4): p. 331-344.

15. ANSI/ASHRAE, Standard 62.2-2019 Ventilation and Acceptable Indoor Air Quality in Residential Buildings. 2019, ASHRAE: Atlanta.

16. ANSI/ASHRAE, Standard 62.1-2019 Ventilation for Acceptable Indoor Air Quality. 2019, ASHRAE: Atlanta.

17. ANSI/ASHRAE, Standard 52.2-2017 Method of Testing General Air-Cleaning Devices for Removal Efficiency by Particle Size. 2017, ASHRAE: Atlanta. 
18. Kowalski, W., W.P. Bahnfleth, and T. Whittam, Filtration of airborne microorganisms: modeling and prediction. ASHRAE TRANS, 1999. 105: p. 4-17.

19. Nicas, M., W.W. Nazaroff, and A. Hubbard, Toward Understanding the Risk of Secondary Airborne Infection: Emission of Respirable Pathogens. Journal of Occupational and Environmental Hygiene, 2005. 2(3): p. 143-154.

20. Duguid, J.P., The size and the duration of air-carriage of respiratory droplets and droplet-nuclei. Epidemiology and Infection, 1946. 44(6): p. 471-479.

21. Milton, D.K., M.P. Fabian, B.J. Cowling, M.L. Grantham, and J.J. McDevitt, Influenza virus aerosols in human exhaled breath: particle size, culturability, and effect of surgical masks. PLoS pathogens, 2013. 9(3).

22. Leconte, S., G. Liistro, P. Lebecque, and J.-M. Degryse, The objective assessment of cough frequency: accuracy of the LR102 device. Cough, 2011. 7(1): p. 11.

23. Lindsley, W.G., F.M. Blachere, R.E. Thewlis, A. Vishnu, K.A. Davis, G. Cao, J.E. Palmer, K.E. Clark, M.A. Fisher, R. Khakoo, and D.H. Beezhold, Measurements of airborne influenza virus in aerosol particles from human coughs. PLoS One, 2010. 5(11): p. e15100.

24. Lai, A.C., Particle deposition indoors: a review. Indoor air, 2002. 12(4): p. 211-214.

25. Reed, C.H., L.A. Wallace, and S.J. Emmerich, Deposition Rates of Fine and Coarse Particles in Residential Buildings: Literature Review and Measurements in an Occupied Townhouse, NISTIR 7068. 2003, U.S. National Institute of Standards and Technology: Gaithersburg.

26. Lai, A.C.K. and W.W. Nazaroff, MODELING INDOOR PARTICLE DEPOSITION FROM TURBULENT FLOW ONTO SMOOTH SURFACES. Journal of Aerosol Science, 2000. 31(4): p. 463-476.

27. Hussein, T., L. Kubincová, L. Džumbová, A. Hruška, P. Dohányosová, J. Hemerka, and J. Smolík, Deposition of aerosol particles on rough surfaces inside a test chamber. Building and Environment, 2009. 44(10): p. 2056-2063.

28. Howard-Reed, C., L.A. Wallace, and S.J. Emmerich, Effect of ventilation systems and air filters on decay rates of particles produced by indoor sources in an occupied townhouse. Atmospheric Environment, 2003. 37(38): p. 5295-5306.

29. Long, C.M., H.H. Suh, P.J. Catalano, and P. Koutrakis, Using Time- and Size-Resolved Particulate Data To Quantify Indoor Penetration and Deposition Behavior. 2001. p. 2089-2099.

30. Zhao, H. and B. Stephens, Using a combined instrumentation system to measure the penetration of ambient ozone and fine and ultrafine particulate matter into residential buildings, in THE 14TH INTERNATIONAL CONFERENCE OF INDOOR AIR QUALITY AND CLIMATE. 2016: Ghent, Belgium.

31. El Orch, Z., B. Stephens, and M.S. Waring, Predictions and determinants of size-resolved particle infiltration factors in single-family homes in the U.S. Building and Environment, 2014. 74: p. 106118.

32. Emmerich, S.J. and S.J. Nabinger, Measurement and Simulation of the IAQ Impact of Particle Air Cleaners in a Single-Zone Building. HVAC\&R Research, 2001. 7(3): p. 223-244.

33. AHAM, Method for Measuring Performance of Portable Household Electric Room Air Cleaners AHAM AC-1-2019. 2019, Association of Home Appliance Manufacturers. 